\title{
Article
}

\section{Non-Vitamin K Antagonist Oral Anticoagulants and Risk of Myocardial Infarction in Patients with Atrial Fibrillation with or without Percutaneous Coronary Interventions: A Meta-Analysis}

\author{
Stefan Grajek ${ }^{1}$, Marta Kałużna-Oleksy ${ }^{1, *(D)}$, Jolanta M. Siller-Matula ${ }^{2,3}$, Maksymilian Grajek ${ }^{4}$ \\ and Michał Michalak ${ }^{5}$ \\ 1 1st Department of Cardiology, Poznan University of Medical Sciences, 61-848 Poznan, Poland; \\ stefan.grajek@skpp.edu.pl \\ 2 Department of Internal Medicine II, Division of Cardiology, Medical University of Vienna, \\ 1090 Vienna, Austria; jolanta.siller-matula@skpp.edu.pl \\ 3 Center for Preclinical Research and Technology (CEPT), Department of Experimental and Clinical \\ Pharmacology, Medical University of Warsaw, 02-097 Warsaw, Poland \\ 4 International School of Poznan, 60-147 Poznan, Poland; maksymilian.grajek@skpp.edu.pl \\ 5 Department of Computer Science and Statistics, Poznan University of Medical Sciences, \\ 60-806 Poznan, Poland; michal@ump.edu.pl \\ * Correspondence: mail: marta.kaluzna@wp.pl; Tel.: +502-896-932
}

\section{check for} updates

Citation: Grajek, S.; Kałużna-Oleksy, M.; Siller-Matula, J.M.; Grajek, M.; Michalak, M. Non-Vitamin K Antagonist Oral Anticoagulants and Risk of Myocardial Infarction in Patients with Atrial Fibrillation with or without Percutaneous Coronary Interventions: A Meta-Analysis. J. Pers. Med. 2021, 11, 1013. https:// doi.org/10.3390/jpm11101013

Academic Editor: Jacek Bil

Received: 16 August 2021

Accepted: 29 September 2021

Published: 9 October 2021

Publisher's Note: MDPI stays neutral with regard to jurisdictional claims in published maps and institutional affiliations.

Copyright: (c) 2021 by the authors. Licensee MDPI, Basel, Switzerland. This article is an open access article distributed under the terms and conditions of the Creative Commons Attribution (CC BY) license (https:// creativecommons.org/licenses/by/ $4.0 /)$.

\begin{abstract}
The study aimed to assess the risk of myocardial infarction (MI) and major adverse cardiac events during non-vitamin $\mathrm{K}$ antagonist oral anticoagulants (NOAC) compared to warfarin therapy in patients with atrial fibrillation (AF), both treated and not treated with percutaneous coronary interventions (PCI). In a systematic search, we selected eight randomized clinical trials with a total of 81,943 patients. Dabigatran, compared to warfarin, significantly increased the risk of MI (relative risk [RR] 1.38, 95\% CI 1.14-1.67), while the FXa inhibitors' effect did not differ significantly from warfarin (RR 0.96, 95\% CI 0.86-1.09). The RR comparison between analyzed subgroups (dabigatran vs. FXa inhibitors) showed a significant difference $\left(\mathrm{Chi}^{2}=9.51, \mathrm{df}=1, p=0.002\right)$. In a network metaanalysis, dabigatran $110 \mathrm{mg}$ b.i.d. increased the risk of MI compared to warfarin, apixaban, edoxaban, and rivaroxaban. Also, dabigatran $150 \mathrm{mg}$ b.i.d. increased the risk of MI compared to warfarin, apixaban, and rivaroxaban. Moreover, we tried to estimate the treatment ranking of the best therapy for MI prevention in patients with AF treated with PCI. Rivaroxaban had a $90 \%$ probability of being ranked the best therapy for MI prevention, whereas dabigatran $110 \mathrm{mg}$ had an $8.2 \%$ probability. Dabigatran $150 \mathrm{mg}$ was the most effective in stroke prevention (94\% probability). Each NOAC is associated with a different risk of MI. Furthermore, we should consider FXa inhibitors as the first line NOACs in AF and coronary artery disease patients. PROSPERO ID CRD42020179808.
\end{abstract}

Keywords: coronary artery disease; probability; VKA; warfarin; NOAC; percutaneous revascularization

\section{Introduction}

For years, the standard triple antithrombotic therapy (TAT) containing vitamin $\mathrm{K}$ antagonist (VKA), P2Y12 inhibitor (mainly clopidogrel), and aspirin was recommended in patients with atrial fibrillation (AF) treated with percutaneous coronary interventions (PCI). However, the increase in bleeding complications is a serious limitation of this treatment. Two randomized controlled trials (RCTs) showed a significant reduction of hemorrhagic complications in patients treated with dual antithrombotic therapy (DAT) containing VKA and clopidogrel or aspirin [1,2]. The possibility of shortening TAT to 6 weeks with further DAT to 6 months was also pointed out [2]. The introduction of new non-VKA oral anticoagulants (NOAC) has changed the therapeutic strategy. Several RCTs 
compared DAT containing NOAC and P2Y12 inhibitor with standard TAT [3-6]. All studies showed a significant reduction in hemorrhagic complications with no apparent effect on thromboembolic complications and major adverse cardiac events (MACE). The results were confirmed in subsequent meta-analyses, favoring DAT over TAT [7-11]. However, two most recent meta-analyses (constructed on the same RCTs) have shown that on DAT, a significant reduction in the risk of hemorrhagic complications (about 40-50\%) is accompanied by an increase in the risk of myocardial infarction (MI) and stent thrombosis (ST) [12,13].

The researchers suggest an individualized administration time of TAT (NOAC, P2Y12 inhibitor, and aspirin) directly after PCI with a transition to DAT during prolonged treatment $[14,15]$. After stent implantation, events such as stent thrombosis (ST) or myocardial infarction (MI) depend on the implantation technique and the type of a stent, the complexity of coronary artery lesions, and appropriate pharmacological support. Dual antiplatelet therapy (DAPT) compared to single antiplatelet therapy (SAPT) gives better protection against MACE, although it increases the risk of bleeding complications. Regardless of the $\mathrm{PCI}$ procedure, some NOACs in patients with AF may increase the risk of MI.

Many meta-analyses have shown that dabigatran treatment leads to a significant increase in the risk of MI [16-22]. However, these analyses were published before the publication of the RE-DUAL PCI study [4], included patients with AF as well as with sinus rhythm, and NOACs were used for different indications (prevention of thromboembolic events, deep vein thrombosis, acute coronary syndrome [ACS]). Furthermore, none of these mentioned above studies concerned AF patients qualified for PCI; therefore, DAT (containing NOAC) was not compared with standard TAT. Moreover, dabigatran was compared with different comparators (placebo/aspirin, warfarin, enoxaparin). Therefore, we present a meta-analysis assessing the risk of MI and MACE during NOAC therapy compared to VKA in patients with AF, both treated and not treated with PCI.

\section{Materials and Methods}

\subsection{The Search Strategy and Selection Criteria}

We conducted a systematic search of studies in PubMed, Embase, the Cochrane Library, and Web of Science until 22 March 2020. We used the following keywords: AF, PCI, ACS, chronic coronary syndrome (CCS), coronary stenting, warfarin, dabigatran, apixaban, rivaroxaban, edoxaban, VKA, "dual antithrombotic therapy", and "triple antithrombotic therapy". Further analyses included studies that fulfilled the following criteria [3-6,23-26]:

(a) Only Phase III RCTs in patients with AF treated with oral anticoagulants (OAC) containing two arms, NOAC vs. warfarin, were analyzed.

(b) Only RCTs with AF patients undergoing PCI for ACS or CCS and containing two arms, DAT (NOAC + P2Y12) vs. standard TAT, were analyzed.

(c) All studies with included information on at least three following endpoints: death, stroke, and MI. We analyzed in detail the data contained in the publication and the accompanying Supplementary Materials. Two co-authors (SG and MM) performed the review and qualification for the analysis, and the third co-author (MKO) completed the final evaluation.

(d) Clinical observational studies, data registers (a real-world registry-RWD), review papers, and comments were excluded.

\subsection{Study Outcomes}

Study outcomes were thrombo-ischemic complications (efficacy endpoints): death, stroke, MI, ST, trial-defined MACE, and cardiovascular death. In addition, the RE-LY study assessed vascular death or cardiac death [23]. Ischemic and thrombo-embolic complications defined as MACE are presented in Table S1B.

\subsection{Data Synthesis and Analysis}

The methodological quality of RCTs was assessed using the Cochrane Collaboration tool for assessing the risk of bias. For each clinical trial, we assessed bias qualitatively as 
low, unclear, or high (Supplementary Table S2). The assessment was made independently by two authors (SG and MM). A meta-analysis comparing the results of individual NOACs vs. warfarin was performed using a random model, which considered between-study variance-tau-squared. Random effects models are more conservative, leading the estimates with wider confidence intervals. In case $\tau^{2}$ was zero, the pooled estimate of the random model was corresponded to those from the fixed-effect model. As a measure of the effect, the Mantel-Haenszel relative risk (RR) was used with a 95\% confidence interval (CI). A sensitivity analysis was performed by excluding the results of $30 \mathrm{mg}$ edoxaban from the ENGAGE AF-TIMI study.

Furthermore, when we evaluated three-arm studies (two different doses and a control group), the analysis was performed twice. First, performing the analysis separately to different dosages, which required doubling the events and sample size of the control group. Due to this approach, we could get an estimate of a particular dose. In the second approach, we combined the results of different dosages into one group vs. control. This approach maintained a real number of events in the control group, but as a result, the obtained estimate reflected artificial dosage (non-existing one). Both results are presented in the Supplementary Materials. However, if results remained consistent across the different models, then we considered them robust. Additionally, we analyzed a difference between the effects obtained from the drug's classes comparison-direct thrombin inhibitors (DTI) vs. warfarin and factor Xa inhibitors (FXa inhibitors) vs. warfarin. The calculations were performed using Review Manager (RevMan 5.3 Cochrane Community, Copenhagen: the Nordic Cochrane Centre, the Cochrane Collaboration, 2014).

For comparisons between individual drugs as well as each of them with warfarin, we used a network meta-analysis (network plot) (Supplementary Figure S44). We analyzed endpoints for which at least two direct studies of the particular drug vs. warfarin were available. Therefore, the network analysis was not used for edoxaban $30 \mathrm{mg}$ and cardiovascular death and ST risk assessment. Calculations were performed three times; based on data from the original RELY study and after data correction in the intention-to-treat and on-treatment analysis $[23,27]$.

The indirect analysis of the 'star' type network was performed using Busher's method [28-30]. The network meta-analysis was performed with the mvmet command (STATA). We then estimated the relative probability of ranking each therapy and obtained a hierarchy of competing treatments using SUCRA (surface under the cumulative ranking) with the method proposed by G. Salanti [31], which required estimation of the probability of being the best for a particular therapy. The explanations about SUCRA are included in the Supplementary Materials. The probability was estimated based on the Bayesian model. We assumed uniform distribution as a priori distribution. As a result, we received a posterior normal distribution with mean and variance, where estimators of normal distribution parameters were estimated based on frequentist inference.

The terms "on-treatment" and "intention-to-treat" used in this work are based on the common rule: when the statistical analysis is performed with the recruited sample size, the analysis refers to the group called "intention-to-treat", however when the statistical analysis is performed based on the number of patients who finished the trial, the study refers to the group called "on-treatment".

Calculations were made with STATA 15.1 software (StataCorp LLC, College Station, TX, USA).

\section{Results}

\subsection{Identified Studies Characteristics}

A total of 677 studies were examined for eligibility, of which nine papers were finally selected for eight studies, with a total of 81,943 patients who met the inclusion criteria (Figure 1). $1653(2.1 \%)$ patients had MI. Eight studies presenting two NOAC classes were selected: DTI: RE-LY [23] and RE-DUAL PCI [4]: dabigatran $150 \mathrm{mg} n=6839$, dabigatran $110 \mathrm{mg} n=6996$ (total 13,835), and FXa inhibitors: ROCKET rivaroxaban 
$20 \mathrm{mg}$ [24], PIONEER AF-PCI [3] rivaroxaban 20/15 $\mathrm{mg} n=7840$, ARISTOTLE [25] and AUGUSTUS [5] apixaban $n=11,426$ and ENGAGE AF-TIMI 48 [26] edoxaban $30 \mathrm{mg}$ $n=7034$, edoxaban $60 \mathrm{mg} n=7035$ and ENTRUST-AF PCI [6] edoxaban $60 \mathrm{mg} n=751$ (total 14,820). All NOACs were compared with warfarin. In PIONEER AF-PCI, we included in the analysis the comparison between the dose of rivaroxaban $15 \mathrm{mg}+$ clopidogrel vs. warfarin + clopidogrel + aspirin [3]. In the AUGUSTUS study [5], we analyzed patients treated and untreated with PCI and randomized to apixaban or warfarin group independent of additional aspirin or placebo. All studies were characterized by the high quality of realization (Supplementary Table S2). Three key studies were not included in the analysis-WOEST [1], ISAR-TRIPLE [2], and AVERROES [32]. Warfarin was used in both arms of the first two studies. In the AVERROES study in AF patients, the efficacy of apixaban vs. aspirin was compared [32]. The study details are presented in Tables 1 and 2.

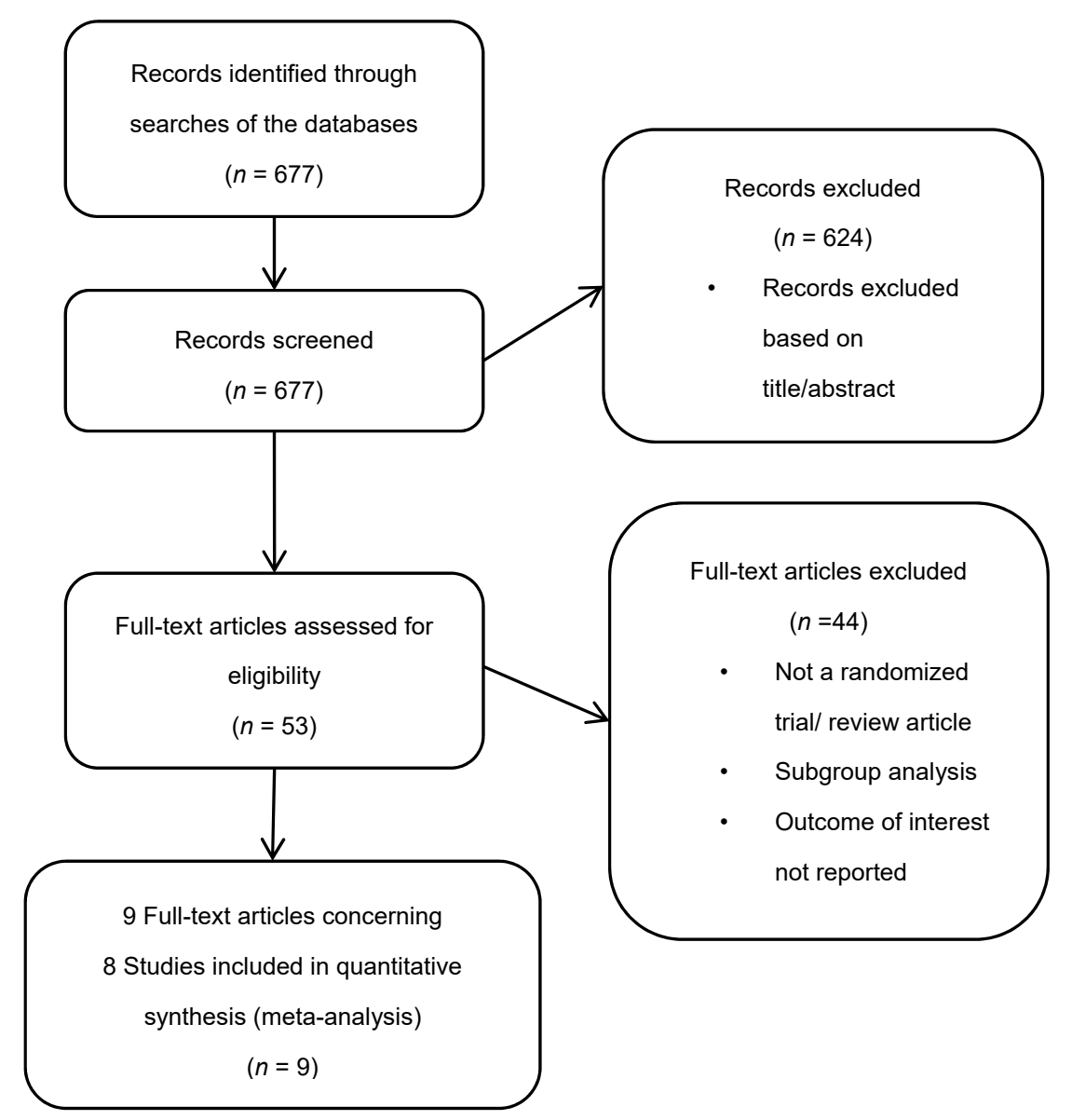

Figure 1. Flowchart of literature search.

We analyzed the following endpoints: overall mortality, stroke, MI, MACE, ST, and cardiovascular or cardiac death. The first three were available in all eight studies. For the MI data in the RE-LY study, we used data from the initial study and the later version after correcting data made by authors [23,33]. The original RE-LY results did not include MACE rates [23]. In the re-analysis, Hohnloser et al. presented MI, MACE, and CD results in the intention-to-treat and on-treatment analysis [27]. Thus, we performed three comparisons for MI and two comparisons for MACE and cardiac death. In the RE-DUAL PCI study, only overall mortality was presented [4]. In the RE-LY study, overall mortality and vascular death were reported, while in the re-analysis by Hohnloser et al., the cardiac death rate was also presented $[23,27]$. We obtained ST data only from four studies comparing DAT vs. TAT [3-6]. 
Table 1. Characteristics of patients in clinical trials included in the meta-analysis and not treated with PCI.

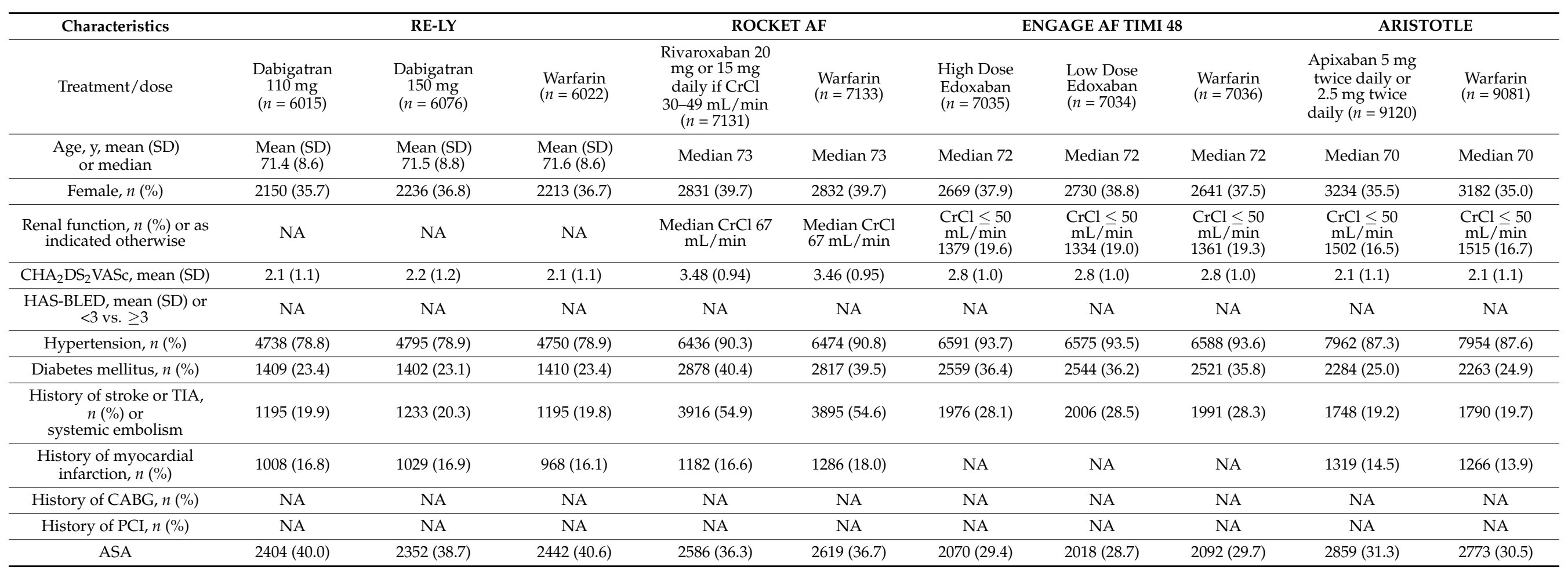

ASA—aspirin, CABG—coronary artery bypass grafting, $\mathrm{CrCl}$-creatinine clearance, $\mathrm{PCI}$ - percutaneous angioplasty, TIA—transient ischemic attack. 
Table 2. Characteristics of patients in clinical trials included in the meta-analysis and treated with PCI.

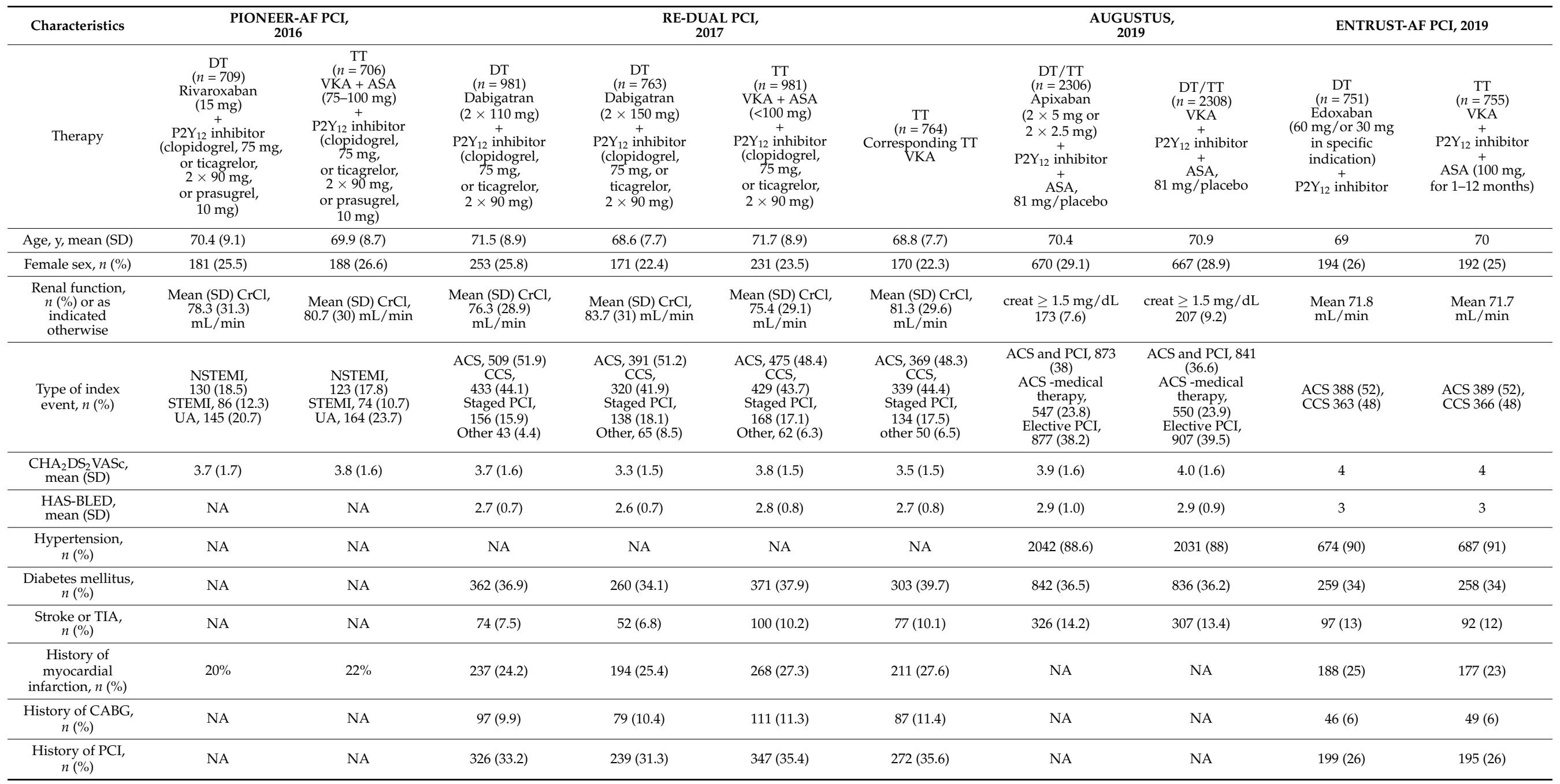

ASA—aspirin, $\mathrm{CABG}$ - coronary artery bypass grafting, $\mathrm{CrCl}$-creatinine clearance, $\mathrm{PCI}$ - percutaneous angioplasty, TIA—transient ischemic attack. 


\subsection{Results of the Standard Meta-Analysis}

\subsubsection{Myocardial Infarction}

Dabigatran compared to warfarin significantly increased the risk of MI (RR 1.38, 95\% CI 1.14-1.67). The effect of FXa inhibitors did not differ significantly from warfarin (RR 0.96, 95\% CI 0.86-1.09); however, the comparison of dabigatran vs. FXa inhibitors showed a significant difference $\left(\mathrm{Chi}^{2}=9.51, \mathrm{df}=1, p_{\text {interaction }}=0.002\right.$; Figure $\left.2 \mathrm{~A}\right)$. Similarly, in the model with combined dosages, the results remained consistent: dabigatran vs. warfarin (RR 1.38, 95\% CI 1.08-1.74); FXa inhibitors vs. warfarin (RR 0.95, 95\% CI 0.84-1.07); $p_{\text {interaction }}$ for dabigatran vs. FXa inhibitors $p=0.006$ (Figure 2B).

A

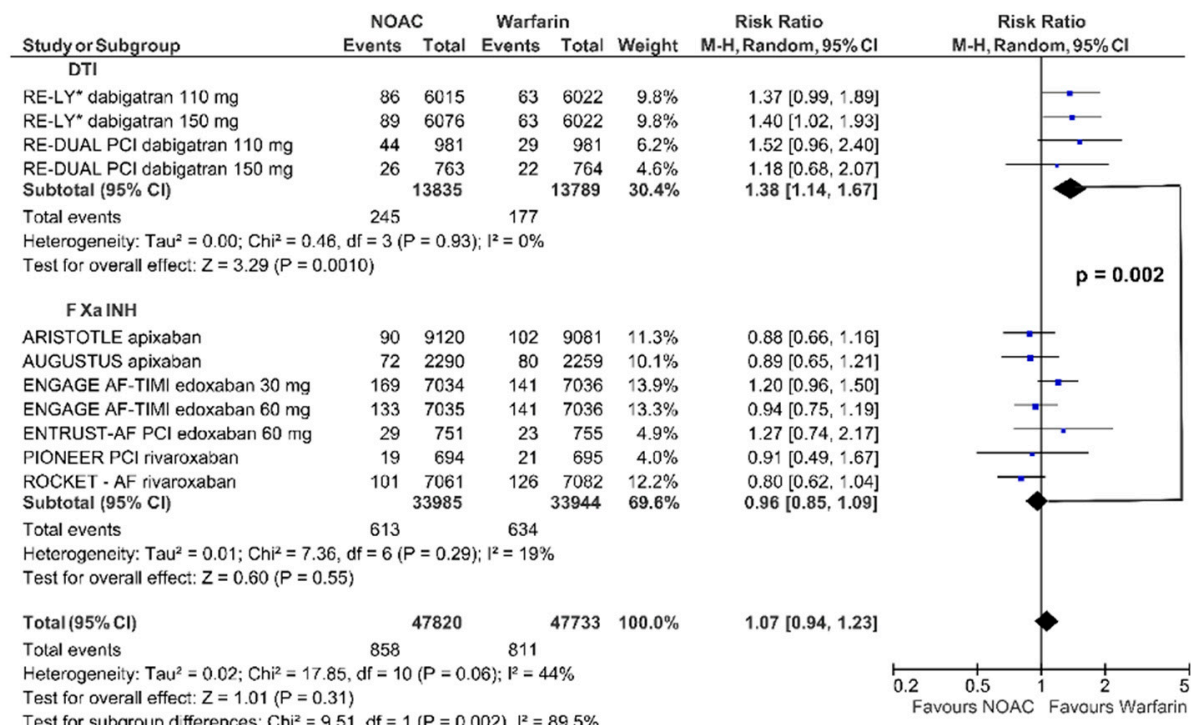

B

\begin{tabular}{|c|c|c|c|c|c|c|c|c|}
\hline Study or Subgroup & \multicolumn{2}{|c|}{ NOAC } & Warfarin & Irin & Weight & $\begin{array}{c}\text { Risk Ratio } \\
\text { M-H, Random, } 95 \% \mathrm{Cl} \\
\end{array}$ & \multicolumn{2}{|c|}{$\begin{array}{c}\text { Risk Ratio } \\
\text { M-H, Random, } 95 \% \mathrm{Cl}\end{array}$} \\
\hline \multicolumn{9}{|l|}{ DTI } \\
\hline$R E-L Y^{*}$ dabigatran & 175 & 12091 & 63 & 6022 & $14.7 \%$ & $1.38[1.04,1.84]$ & & $=$ \\
\hline $\begin{array}{l}\text { RE-DUAL PCI dabigatran } \\
\text { Subtotal }(95 \% \mathrm{Cl})\end{array}$ & 70 & $\begin{array}{r}1744 \\
13835\end{array}$ & 29 & $\begin{array}{r}981 \\
7003\end{array}$ & $\begin{array}{r}9.0 \% \\
23.7 \%\end{array}$ & $\begin{array}{r}1.36[0.89,2.08] \\
1.38[1.08,1.74]\end{array}$ & & \\
\hline \multirow{2}{*}{\multicolumn{9}{|c|}{$\begin{array}{l}\text { Total events } \\
\text { Heterogeneity: } \mathrm{Tau}^{2}=0.00 ; \mathrm{Chi}^{2}=0.01, \mathrm{df}^{\mathrm{N}}=1(\mathrm{P}=0.94) ; \mathrm{I}^{2}=0 \%\end{array}$}} \\
\hline & & & & \multicolumn{5}{|c|}{$\begin{array}{l}\text { Heterogeneity: } \text { Tau }^{2}=0.00 ; \text { Chi }^{2}=0.01, d f=1(P=0.94) ; 1^{2}=0 \% \\
\text { Test for overall effect: } Z=2.63(P=0.009)\end{array}$} \\
\hline & & & & & & & & $p=0.006$ \\
\hline \multicolumn{9}{|l|}{ FXaINH } \\
\hline ARISTOTLE apixaban & 90 & 9120 & 102 & 9081 & $15.0 \%$ & $0.88[0.66,1.16]$ & & \\
\hline AUGUSTUS apixaban & 72 & 2290 & 80 & 2259 & $13.3 \%$ & $0.89[0.65,1.21]$ & & \\
\hline ENGAGE-AF-TIMI edoxaban & 302 & 14069 & 141 & 7036 & $20.4 \%$ & $1.07[0.88,1.31]$ & & \\
\hline ENTRUST-AF PCl edoxaban $60 \mathrm{mg}$ & 29 & 751 & 23 & 755 & $6.3 \%$ & $1.27[0.74,2.17]$ & & 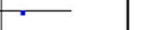 \\
\hline PIONEER PCI rivaroxaban & 19 & 694 & 21 & 695 & $5.1 \%$ & $0.91[0.49,1.67]$ & & \\
\hline $\begin{array}{l}\text { ROCKET - AF rivaraxaban } \\
\text { Subtotal } / 95 \% \mathrm{Cl} \text { ) }\end{array}$ & 101 & $\begin{array}{r}7061 \\
33985\end{array}$ & 126 & $\begin{array}{r}7082 \\
26908\end{array}$ & $\begin{array}{l}16.3 \% \\
76.3 \%\end{array}$ & $0.80[0.62,1.04]$ & & \\
\hline \multirow{4}{*}{\multicolumn{9}{|c|}{$\begin{array}{l}\text { Total events } \\
\text { Heterogeneity: } \text { Tau }^{2}=0.00 ; \mathrm{Chi}^{2}=4.60, \mathrm{df}^{\mathrm{f}}=5(\mathrm{P}=0.47) ; \mathrm{I}^{2}=0 \% \\
\text { Test for overall effect: } Z=0.89(\mathrm{P}=0.38)\end{array}$}} \\
\hline & & & & & & & & \\
\hline & & & & & & & & \\
\hline & & & & & & & & \\
\hline Total $(95 \% \mathrm{Cl})$ & & 47820 & & 33911 & $100.0 \%$ & $1.03[0.88,1.20]$ & & \\
\hline Total events & 858 & & 585 & & & & & \\
\hline Heterogeneity: Tau$^{2}=0.02 ; \mathrm{Chi}^{2}=12$ & $6, d f=7$ & $(P=0.1 C$ & $0) ; 1^{2}=42$ & & & & & \\
\hline Test for overall effect: $Z=0.37(P=0$ & & & & & & & $\begin{array}{l}0.2 \\
\text { Favours NOAC }\end{array}$ & Favours W \\
\hline
\end{tabular}

Figure 2. The meta-analysis results for myocardial infarction. * original data from RE-LY study [23]. (A)—dabigatran dose dependent analysis; (B)—dabigatran dose independent analysis.

Considering the intention-to-treat analysis [30,31], the result was similar. Dabigatran increased the risk of MI (RR 1.31, 95\% CI 1.10-1.58), but not FXa inhibitors (RR 0.96, $95 \%$ CI $0.85-1.09, \mathrm{Chi}^{2}=7.66 \mathrm{df}=1(p=0.006)$ (Figure 3A). The second approach yielded the same results: dabigatran vs. warfarin (RR 1.31, 95\% CI 1.05-1.64); FXa inhibitors vs.

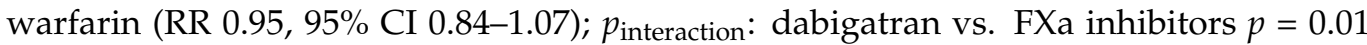
(Figure 3B). 
This result was confirmed in the on-treatment analysis: dabigatran (RR 1.29, 95\% CI 1.06-1.57) vs. FXa inhibitors (RR 0.96, 95\% CI 0.85-1.09, Chi $^{2}$ 6.17, df =1, p = 0.01) (Figure $4 \mathrm{~A}$ ). The second model yielded the following results: dabigatran vs. warfarin (RR 1.29, 95\% CI 1.01-1.64); FXa inhibitors vs. warfarin (RR 0.95, 95\% CI 0.84-1.07); $p_{\text {interaction: }}$ dabigatran vs. FXa inhibitors $p=0.02$ (Supplementary Figure S26A).

A

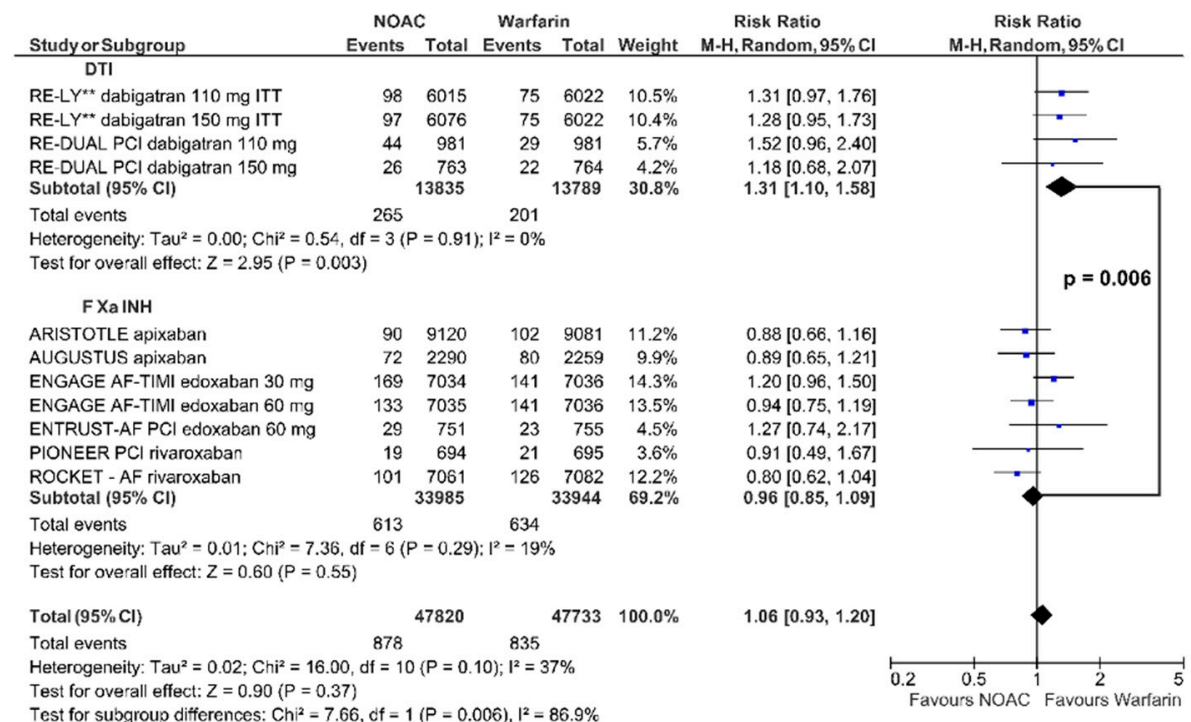

B

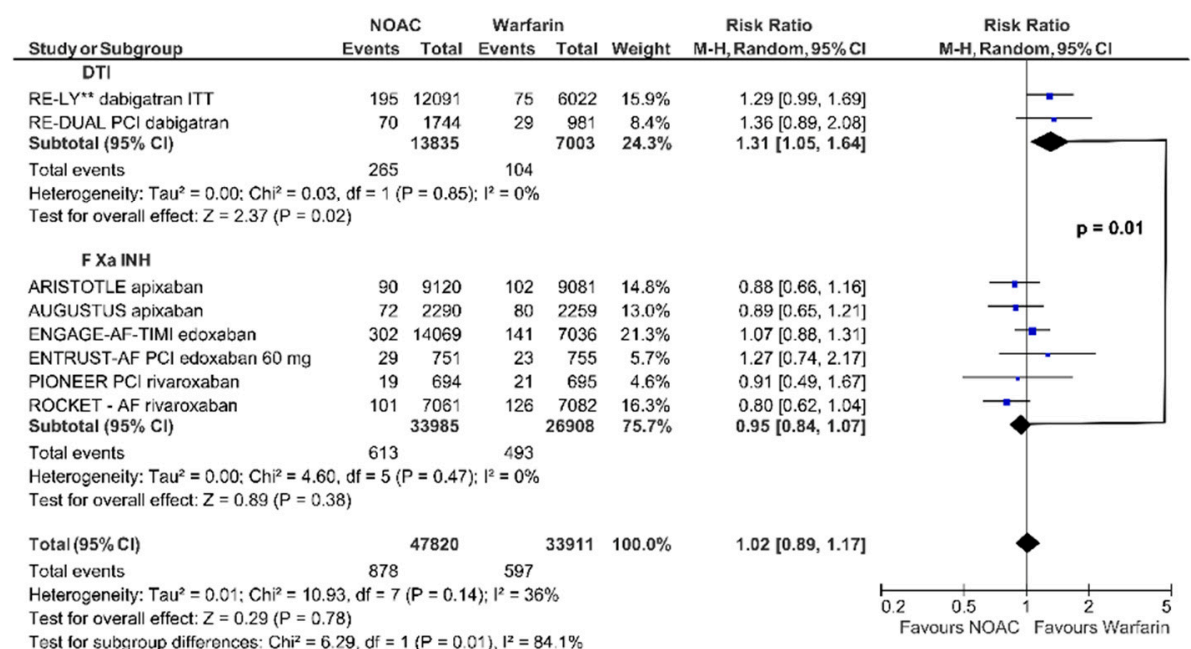

Figure 3. The meta-analysis results for myocardial infarction-the reanalysis RE-LY: intention to treat data. ${ }^{* *}$ results from a reanalysis of the RE-LY study [27]; (A)—dabigatran dose dependent analysis; (B) — dabigatran dose independent analysis.

In the sensitivity analysis, after excluding edoxaban $30 \mathrm{mg}$, the risk of $\mathrm{MI}$ in patients treated with FXa inhibitors did not change (Supplementary Figures S20, S24 and S28). The results remained consistent also in the second model (combined dosages) (Supplementary Figures S20A, S24A and S28A).

\subsubsection{Major Adverse Cardiac Events}

Dabigatran vs. warfarin did not significantly reduce the risk of MACE both in the intention-to-treat (RR 0.94, 95\% CI 0.86-1.03) and in on-treatment analysis (RR 0.94, 95\% CI 0.84-1.06, Figure 4A), while FXa inhibitors significantly reduced the risk of MACE (RR 0.92, 95\% CI 0.87-0.97). The exclusion of $30 \mathrm{mg}$ edoxaban did not significantly affect the results (Supplementary Figures S12 and S16). The pooled data showed that NOAC reduced 
the risk of MACE by $8 \%$ (RR $0.92,95 \%$ CI $0.88-0.96$, Figure 4 A) compared to warfarin. We obtained the consistent results taking a second model in which the events of different dosages presented in one study were merged: intention-to-treat data: dabigatran vs. warfarin (RR 0.94, 95\% CI 0.86-1.02); FXa inhibitors vs. warfarin (RR 0.91, 95\% CI 0.87-0.96) (Supplementary Figure S10A); and on-treatment analysis: dabigatran vs. warfarin (RR 0.93, 95\% CI 0.83-1.05); FXa inhibitors vs. warfarin (RR 0.91, 95\% CI 0.87-0.96) (Supplementary Figure S14A); NOACs, all together vs. warfarin (RR 0.91, 95\% CI 0.88-0.96).

A

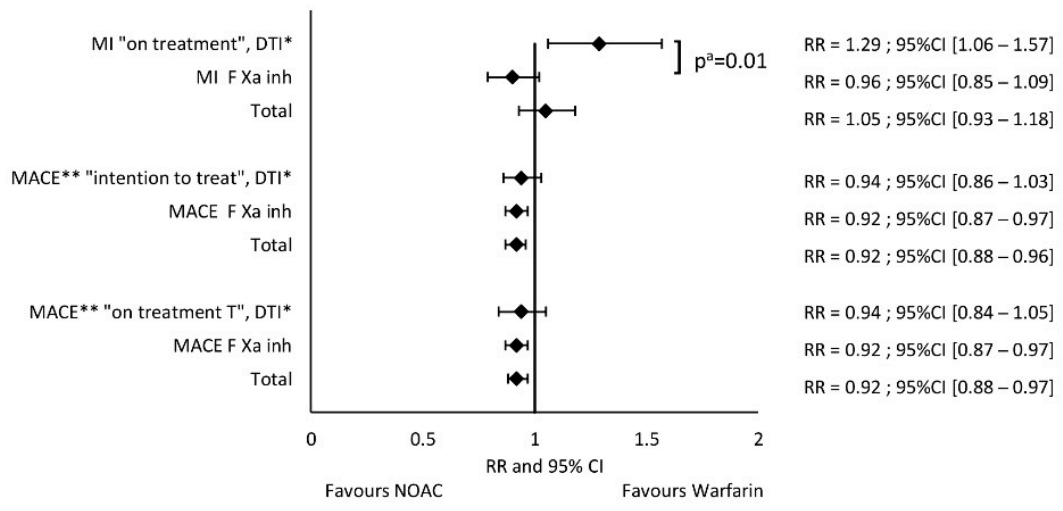

B

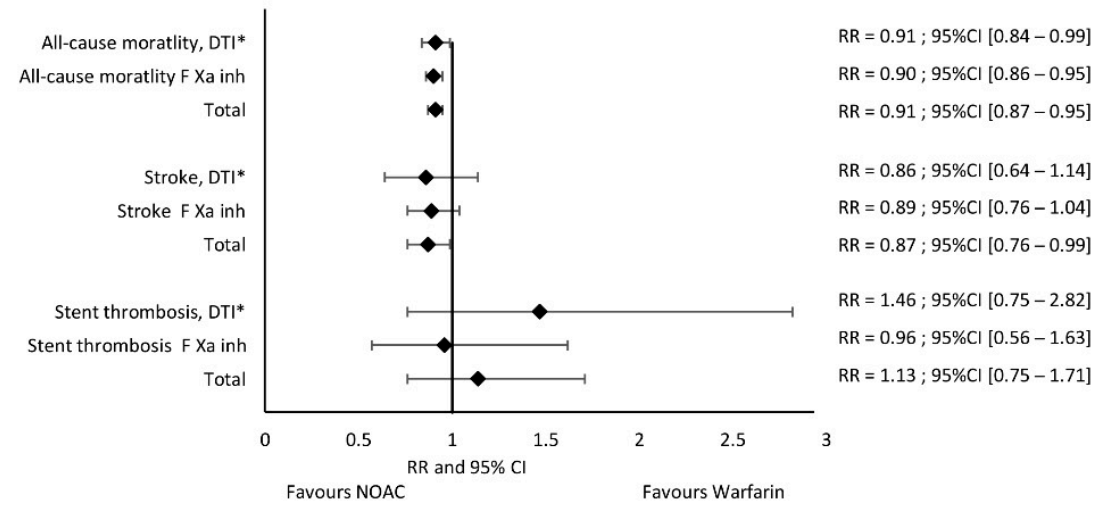

C

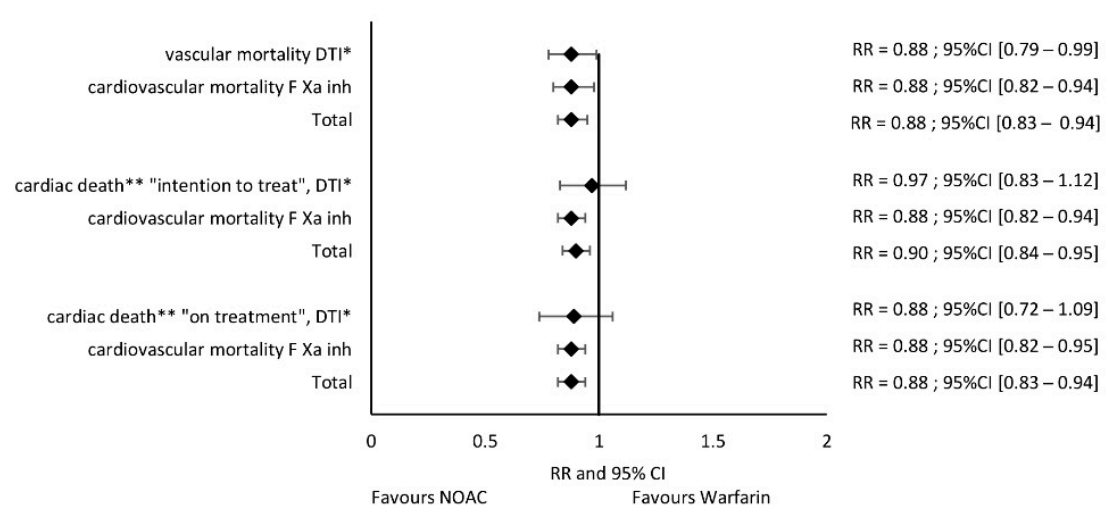

Figure 4. Forest plot of the relative risk of efficacy endpoints: (A): MI, MACE; (B): overall mortality, stroke, stent thrombosis; (C): cardiovascular mortality. ${ }^{a}{ }-p$-value for subgroup differences; ${ }^{*}$ direct thrombin inhibitor-dabigatran; ${ }^{* *}$ results from the reanalysis of the RE-LY study [27].

\subsubsection{All-Cause Mortality}

Both dabigatran and FXa inhibitors compared to warfarin significantly reduced overall mortality with RR $0.91,95 \%$ CI $0.84-0.99$ and RR $0.90,95 \%$ CI $0.86-0.95$, respectively (NOAC all together: RR 0.91 95\% CI 0.87-0.96, Figure 4B). After excluding edoxaban 
$30 \mathrm{mg}$, the estimated risk indicators did not change significantly (Supplementary Figure S4). After combining data for different dosages, the results were as follows: dabigatran vs. warfarin-RR 0.91, 95\% CI 0.82-1.01; FXa inhibitors vs. warfarin-RR 0.90, 95\% CI 0.85-0.96; NOAC all together-RR 0.90 95\% CI 0.86-0.95 (Supplementary Figure S2A). Further excluding data with edoxaban $30 \mathrm{mg}$ led to the same results (Supplementary Figure S4A).

\subsubsection{Stroke}

Compared to warfarin, both dabigatran and FXa inhibitors similarly reduced the risk of stroke: RR 0.86, 95\% CI 0.65-1.14 and RR 0.89, 95\% CI 0.76-1.04, respectively. We also confirmed this in the pooled analysis: NOACs vs. warfarin (RR 0.87, 95\% CI 0.76-0.99, Figure 4B). After excluding edoxaban $30 \mathrm{mg}$, for the remaining FXa inhibitors vs. warfarin, RR for stroke was 0.84, 95\% CI 0.76-0.92 (Supplementary Figure S8). The second model provided the following results: dabigatran vs. warfarin-RR 0.81, 95\% CI 0.67-0.98; FXa inhibitors vs. warfarin-RR 0.86, 95\% CI 0.74-1.01; NOAC together-RR 0.86 95\% CI 0.76-0.97 (Supplementary Figure S6A). After exclusion of edoxaban $30 \mathrm{mg}$, we observed the significant stroke reduction for both types of NOAC: dabigatran vs. warfarin-RR 0.81 , 95\% CI 0.67-0.98; FXa inhibitors vs. warfarin-RR 0.84, 95\% CI 0.76-0.92); and NOAC together-RR 0.83 95\% CI 0.76-0.90 (Supplementary Figure S8A).

\subsubsection{Stent Thrombosis}

ST was evaluated in only four studies: PIONEER [3], RE-DUAL PCI [4], AUGUSTUS [5], and ENTRUST-AF PCI [6]. In total, the use of NOACs compared to warfarin was associated with a similar risk of ST (RR 1.13,95\% CI 0.75-1.71). Dabigatran increased the risk of ST by 1.46-fold (RR 1.46, 95\% CI 0.75-2.82), while FXa inhibitors decreased this risk (RR 0.96, 95\% CI 0.67-1.62, Figure 4B). The second model provided similar results: dabigatran-RR 1.55, 95\% CI 0.69-3.46; FXa inhibitors vs. warfarin-RR 0.96, 95\% CI 0.56-1.63; NOAC all together-RR 1.11 95\% CI 0.71-1.73 (Supplementary Figure S30A).

\subsubsection{Cardiovascular Death}

Cardiovascular death was not reported in ARISTOTLE and REDUAL PCI, while RELY reported vascular death [23] and after data correction-cardiac death [27] (Supplementary Table S1C). Dabigatran vs. warfarin moderately (12\%) but significantly reduced cardiovascular death risk (RR 0.88, 95\% CI 0.79-0.99, Figure 4C). After data correction [27] in intention-to-treat and on-treatment analyses, RR for cardiovascular death was 0.97 (95\% CI 0.83-1.12) and RR 0.88 (95\% CI 0.72-1.09), respectively (Figure 4C). FXa inhibitors compared to warfarin also moderately reduced the risk of cardiovascular death (RR 0.88 , 95\% CI 0.82-0.94, Figure 4C). In all three comparisons, NOAC vs. warfarin significantly reduced the relative risk of cardiovascular death in the range of $10-12 \%$ (RR $0.88,95 \% \mathrm{CI}$ 0.83-0.94, RR 0.90, 95\% CI 0.84-0.96 and RR 0.88, 95\% CI 0.82-0.94, Figure 4C). The result was consistent after excluding edoxaban $30 \mathrm{mg}$ (Supplementary Figures S34, S38 and S42). In the second model, dabigatran did not significantly reduce the cardiovascular death risk (RR 0.88, 95\% CI 0.77-1.01, Supplementary Figure S32A), and after data correction [27] in intention-to-treat and on-treatment analyses, the results were as follows: RR 0.97, 95\% CI 0.81-1.16 (Supplementary Figure S36A) and RR 0.89, 95\% CI 0.71-1.10 (Supplementary Figure S34A), respectively. In all three comparisons, NOAC vs. warfarin significantly reduced the relative risk of cardiovascular death: RR 0.88,95\% CI 0.81-0.96 (Supplementary Figure S32A); RR 0.88, 95\% CI 0.81-0.96 (Supplementary Figure S36A) and RR 0.89, 95\% CI 0.82-0.96 (Supplementary Figure S40A). Similarly, the result was consistent after excluding edoxaban $30 \mathrm{mg}$ (Supplementary Figures S34A, S38A and S42A).

\subsection{Results of the Network Meta-Analysis}

Dabigatran at the dose of $110 \mathrm{mg}$ b.i.d. as well as at the dose of $150 \mathrm{mg}$ b.i.d. increased the risk of MI compared to warfarin, apixaban, and rivaroxaban (Figure 5). All analyzed drugs except dabigatran $110 \mathrm{mg}$ b.i.d. significantly reduced the risk of MACE (Supplemen- 
tary Tables S7 and S9). The estimated risk indicators for stroke and overall mortality were similar and did not differ between drugs (Supplementary Tables S13 and S15).

\begin{tabular}{|c|c|c|c|c|c|}
\hline $\begin{array}{c}\text { Dabigatran_110mg } \\
\text { RR }(95 \% \mathrm{Cl})\end{array}$ & \multirow{4}{*}{$\begin{array}{l}\text { Dabigatran_150mg } \\
\text { RR }(95 \% \mathrm{Cl})\end{array}$} & & & Treatment 1 & \\
\hline $1.05(0.72-1.55)$ & & & & $\mathbf{M I}^{*}$ & \multirow{3}{*}{ Treatment 2} \\
\hline $1.09(0.75-1.56)$ & & & & MI ${ }^{\star \star}$ "intention to treat" & \\
\hline $1.10(0.75-1.63)$ & & & & $\mathrm{Ml}^{\star \star}$ "on treatment" & \\
\hline $1.60(1.14-2.24)$ & $1.52(1.07-2.15)$ & \multirow{3}{*}{$\begin{array}{l}\text { Apixaban } \\
\text { RR (95\%Cl) }\end{array}$} & & & \\
\hline $1.55(1.12-2.14)$ & $1.43(1.02-2.00)$ & & & & \\
\hline $1.53(1.09-2.15)$ & $1.39(0.98-1.97)$ & & & & \\
\hline $1.43(1.02-2.01)$ & $1.36(0.96-1.93)$ & $0.89(0.66-1.20)$ & \multirow{3}{*}{$\begin{array}{l}\text { Edoxaban_60mg } \\
\text { RR (95\%Cl) }\end{array}$} & & \\
\hline $1.38(0.99-1.92)$ & $1.27(0.91-1.79)$ & $0.89(0.66-1.20)$ & & & \\
\hline $1.37(0.97-1.92)$ & $1.24(0.87-1.77)$ & $0.89(0.66-1.20)$ & & & \\
\hline $1.73(1.20-2.49)$ & $1.64(1.14-2.37)$ & $1.08(0.79-1.48)$ & $0.89(0.66-1.20)$ & \multirow{3}{*}{$\begin{array}{l}\text { Rivaroxaban } \\
\text { RR (95\%CI) }\end{array}$} & \\
\hline $1.67(1.17-2.38)$ & $1.54(1.08-2.19)$ & $1.08(0.79-1.48)$ & $0.89(0.66-1.20)$ & & \\
\hline $1.65(1.14-2.39)$ & $1.50(1.03-2.17)$ & $1.08(0.79-1.48)$ & $0.89(0.66-1.20)$ & & \\
\hline $1.42(1.09-1.84)$ & $1.34(1.02-1.77)$ & $0.88(0.72-1.09)$ & $0.99(0.79-1.23)$ & $0.82(0.65-1.04)$ & \multirow{3}{*}{$\begin{array}{c}\text { Warfarin } \\
\text { RR }(95 \% \mathrm{Cl})\end{array}$} \\
\hline $1.37(1.06-1.76)$ & $1.26(0.97-1.64)$ & $0.88(0.72-1.09)$ & $0.99(0.79-1.23)$ & $0.82(0.65-1.04)$ & \\
\hline $1.35(1.03-1.76)$ & $1.23(0.92-1.63)$ & $0.88(0.72-1.09)$ & $0.99(0.79-1.23)$ & $0.82(0.65-1.04)$ & \\
\hline
\end{tabular}

Figure 5. Direct and indirect comparison between warfarin and NOACs for myocardial infarction. * original data from RE-LY study [23], ** results from reanalysis RE-LY study [27]. The red colour shows significant differences.

\subsection{Results of the Analysis with SUCRA}

We also estimated a hierarchy of competitive treatments using SUCRA. Rivaroxaban doses 20 and $15 \mathrm{mg}$ taken once daily showed the highest probability of being the most effective treatment in reducing the risk of MI (Figure 6), MACE, and overall mortality (Supplementary Tables S4, S6 and S16). Dabigatran $150 \mathrm{mg}$ b.i.d. was the most effective in reducing the risk of stroke. Dabigatran $110 \mathrm{mg}$ b.i.d. had the weakest effect on the ischemic events, whereas apixaban and edoxaban had a moderate impact.

\begin{tabular}{|c|c|c|c|}
\hline \multirow{2}{*}{ Treatment } & MI* & MI** "intention to treat" & MI** "on treatment" $^{*}$ SUCRA \\
\cline { 2 - 4 } & \multicolumn{3}{|c|}{} \\
\hline Rivaroxaban 20/15 & 90.1 & 90.3 & 90.0 \\
\hline Apixaban 5/2,5 mg & 79.1 & 78.8 & 78.5 \\
\hline Edoxaban_60mg & 56.4 & 55.7 & 54.9 \\
\hline Warfarin & $\mathbf{5 2 . 2}$ & $\mathbf{5 1 . 5}$ & $\mathbf{5 0 . 9}$ \\
\hline Dabigatran_150mg & 14.0 & 16.4 & 18.5 \\
\hline Dabigatran_110mg & 8.2 & 7.4 & 7.3 \\
\hline
\end{tabular}

Figure 6. The surface under the cumulative ranking curve (SUCRA) of myocardial infarction. * original data from RE-LY study [23]; ${ }^{* *}$ results from reanalysis RE-LY study [27]. The red numbers refer to warfarin as the comparator for all investigated drugs. 


\section{Discussion}

Dabigatran, in contrast to FXa inhibitors, compared to warfarin significantly increased the risk of MI by 1.38-fold. Comparing dabigatran vs. FXa inhibitors, a significant difference between the risk estimators was shown $(p=0.002)$ (Figure 2). After the correction of the RE-LY data $[23,27,33]$, the observed effect of dabigatran on MI still significantly differed from that of warfarin or FXa inhibitors (Figures 3 and $4 \mathrm{~A}$ ).

NOAC, compared to warfarin, had a favorable risk-benefit profile [34]. However, in the RE-LY study [23] in patients with AF, the number of patients with MI was higher in dabigatran than in the warfarin group. Many meta-analyses showed that dabigatran treatment led to an increased risk of MI [16-22]. These analyses included patients with $\mathrm{AF}$ and sinus rhythm at the same time. Dabigatran was used for various indications (prevention of thromboembolic events, deep vein thrombosis, ACS) and was compared with placebo/aspirin, warfarin, and enoxaparin. Therefore, it is questioned whether the results can be extrapolated to patients with AF undergoing PCI. Data from large RWD did not confirm an increase in the risk of MI during dabigatran treatment [35-39]. However, in patients with $\mathrm{AF}$, the switch from warfarin to dabigatran treatment resulted in an increased risk of MI compared to naive patients [40]. The discrepancies between RCT and RWD findings result from different study designs and different confounding variables. Without questioning the informative value of RWD, RCTs still represent the 'gold standard' of clinical trials [41-45]. We excluded RWD from our analysis, and each of the four drugs was evaluated in two key phase III RCT: in patients with AF and patients with AF and CCS or ACS treated with PCI. In each study, warfarin was the comparator for NOAC. In this homogeneous group of patients, dabigatran in the direct comparison with warfarin significantly increased the risk of MI by about $30 \%$. Moreover, the risk of MI was also significantly higher than the opposite effect of FXa inhibitors vs. warfarin. In our network meta-analysis, taking into account individual NOACs in recommended doses, only in patients treated with dabigatran $150 \mathrm{mg}$ b.i.d. and especially with dabigatran $110 \mathrm{mg}$ b.i.d., we found an increased risk of MI compared to warfarin (Figure 5). Our observations are consistent with the results of previously published network meta-analyses $[18,19,46,47]$. NOACs pooled together compared to warfarin significantly reduced the risk of overall mortality, cardiovascular mortality, stroke, and MACE. After considering the division into classes: DTI and FXa inhibitors, the directions of changes in both subgroups were consistent (Figure 4). The risk of MACE was significantly reduced only in the FXa inhibitors subgroup (Figure 4A). One might suppose that a lower but nonsignificant reduction of MACE and cardiac death in patients treated with dabigatran might have resulted from the increased number of patients with MI. Moreover, a higher risk of ST in these patients also deserves attention (Figure 4B). The final answer may be available from the randomized studies comparing FXa inhibitors and DTI in patients with AF and ACS treated with PCI.

Patients with AF treated with NOAC and undergoing PCI [3-6] differ from patients with AF treated on chronic NOAC therapy [23-26]. They characterize a higher risk of ACS and the necessity of DAPT use (usually clopidogrel + aspirin). However, independent of ACS risk and percentage of patients on chronic NOAC therapy treated with aspirin $(29-40 \%)$ as well as in contrast to FXa inhibitors, dabigatran increased the risk of MI.

The mechanism of increased risk of MI during DTI treatment has not been fully understood. Warfarin suppresses thrombin generation more efficiently than dabigatran [48]. The effects of DTI depend on its plasma concentration, and its activity decreased at trough levels. When the concentrations of DTI decline below therapeutic ranges, the paradoxical impact (enhancement of thrombin generation) might occur.

The mechanism of the paradoxical coagulation activation by DTI may be suppressing the thrombin-thrombomodulin (TM)-induced negative feedback by inhibiting protein-C activation [49]. Artang et al. suggested that at DTI trough levels, the remaining enzymatically active thrombin dissociated from DTI molecules when exposed to tissue factor at the site of a ruptured atherosclerotic plaque, and thrombin generation increased [19]. Direct FXa inhibitors did not enhance thrombin generation in human plasma in the absence 
and the presence of thrombin-thrombomodulin and protein-C. Thus, FXa inhibitors are less prone to induce coagulation [49]. Some authors proved that dabigatran increased platelet reactivity by enhancing the thrombin receptor density (PAR-I PAR-4) on platelets [50]. Others suggested that DTIs therapy increased inflammatory markers in patients with MI [51]. These results provide arguments to justify the increased risk of MI in patients treated with dabigatran.

The benefit of dabigatran for stroke prevention supported the clinical opinion that it "seems to outweigh the small increase in the risk of MI" [41]. However, the situation changed after publishing the first RCT in patients with AF qualified for PCI and treated with standard TAT vs. DAT containing rivaroxaban (PIONEER AF-PCI) [3]. Subsequent studies based on a similar protocol were performed with dabigatran [4], apixaban [5], and edoxaban [6]. They all reported a significant reduction in hemorrhagic complications and the lack of substantial effect on MACE rates. These results started a debate on the optimal combination of OAC and antiplatelet therapy. The discussion focused on antiplatelet treatment and the recommendation of using NOAC over warfarin without considering differences between FXa inhibitors and DTI.

Therefore, we believe that in patients with AF and undergoing PCI, the choice of NOAC (FXa inhibitors vs. DTI) is as important as choosing the optimal antiplatelet therapy (DAPT vs. SAPT). Additionally, using the SUCRA score, we estimated the treatment ranking of the best therapy for MI prevention in patients with AF (Figure 6). Rivaroxaban had a $90 \%$ probability of being ranked the best therapy for MI prevention, whereas dabigatran $110 \mathrm{mg}$ had only an $8.2 \%$ probability.

However, dabigatran $150 \mathrm{mg}$ was the most effective in stroke prevention (a 94\% probability). Conversely, dabigatran $110 \mathrm{mg}$ was the worst in stroke prevention among all analyzed NOACs with a $24.5 \%$ probability. Rivaroxaban was ranked to be the best therapy with respect to MACE and overall mortality. More potent antiplatelet drugs (e.g., ticagrelor) may optimize the risk of MI related to dabigatran therapy, especially at a dose of $110 \mathrm{mg}$ b.i.d., although this strategy needs to be confirmed in randomized trials.

The estimated number needed to harm (NNH) for both doses, including the original publication [23], is 219 (1057-122), while separately 184 and 231 for the $110 \mathrm{mg}$ and $150 \mathrm{mg}$ doses, respectively. The similar estimations from the RE-LY re-analysis [27] are 232 (1949-123) for both doses, and 184 and 268 for $110 \mathrm{mg}$ and $150 \mathrm{mg}$, respectively. These results suggest that the risk of MI in patients treated with dabigatran, though low, is significant and that a higher risk is related to a dose of $110 \mathrm{mg}$.

The newest European Society of Cardiology guidelines on the management of patients with AF and non-ST elevation myocardial infarction [14,15] recommend the $110 \mathrm{mg}$ dose of dabigatran in preference to $150 \mathrm{mg}$ to mitigate the bleeding risk.

Our study proved an increased risk of MI in patients treated with both doses of dabigatran-110 mg and $150 \mathrm{mg}$. Therefore, we recommend that FXa inhibitors should be considered in the first line in patients with AF and concomitant coronary artery disease.

\section{Limitations}

The limitation of our study was the different definitions of endpoints in individual studies-MACE, cardiovascular mortality, or vascular mortality. Another limitation is an indirect comparison of individual drugs through a common comparator-warfarin, because it was not possible to assess direct effects between the analyzed drugs. This is related to the impossibility of evaluating the consistency between direct and indirect effects, which is the basic assumption of the network meta-analysis. However, the advantage of our meta-analysis is that it only applies to randomized studies, which are free of bias. An additional advantage is that each of the analyzed arms was balanced and included patients with AF treated medically and patients with AF and ACS treated with PCI. 


\section{Conclusions}

Each NOAC was associated with a different risk of MI. Dabigatran in both doses characterized a higher risk of MI compared to warfarin and FXa inhibitors. Furthermore, FXa inhibitors should be considered the first line NOACs in patients with AF and coronary artery disease.

Supplementary Materials: The following are available online at https: / www.mdpi.com/article/ 10.3390/jpm11101013/s1. Table S1A: The characteristics of studies included in meta-analysis, Table S1B: MACE (++) and thromboembolic or ischemic end points (+), Table S1C: Characteristics of patients in clinical trials included in the meta-analysis-RE-LY, ROCKET AF, ENGAGE AF TIMI 48, ARISTOTLE, Table S1D: Charcteristics of patients in clinical trials included in the meta-analysisPIONEER-AF PCI, RE-DUAL PCI, AUGUSTUS, ENTRUST-AF-PCI, Table S2: The risk of bias of individual studies by Cochrane Risk Assessment Tool, Table S3: Direct and indirect comparison between Warfarin and NOAC's-MACE** —inetntion-to-treat data, Table S4: Treatment hierarchy assessed by surface under the cumulative ranking (SUCRA) curves-MACE ${ }^{* *}$-intention-to-treat data, Table S5: Direct and indirect comparison between Warfarin and NOAC's-MACE** - ontreatment data, Table S6: Treatment hierarchy assessed by surface under the cumulative ranking (SUCRA) curves-MACE** —on-treatment data, Table S7: Direct and indirect comparison between Warfarin and NOAC's-MI* data, Table S8: Treatment hierarchy assessed by surface under the cumulative ranking (SUCRA) curves- $\mathrm{MI}^{*}$, Table S9: Direct and indirect comparison between Warfarin and NOAC's-MI**-intentio-to-treat data, Table S10: Treatment hierarchy assessed by surface under the cumulative ranking (SUCRA) curves-MI** - intentio-to-treat data, Table S11: Direct and indirect comparison between Warfarin and NOAC's-MI* —on-treatment data, Table S12: Treatment hierarchy assessed by surface under the cumulative ranking (SUCRA) curves-MI** - ontreatment data, Table S13: Direct and indirect comparison between Warfarin and NOAC's—stroke data, Table S14: Treatment hierarchy assessed by surface under the cumulative ranking (SUCRA) curves-stroke data, Table S15: Direct and indirect comparison between Warfarin and NOAC'soverall mortality data, Table S16: Treatment hierarchy assessed by surface under the cumulative ranking (SUCRA) curves-overall mortality data, Figure S1: Flowchart of literature search, Figure S2: The meta-analysis results for all-cause mortality, Figure S2A: The meta-analysis results for all-cause mortality after combining study data with respect to doses, Figure S3: The funnel plot for all-cause mortality, Figure S4: The meta-analysis results for all-cause mortality after excluding ENGAGE AF-TIMI Edoxaban $30 \mathrm{mg}$, Figure S4A: The meta-analysis results for all-cause mortality after excluding ENGAGE AF-TIMI Edoxaban $30 \mathrm{mg}$ and combining study data with respect to doses, Figure S5: The funnel plot for all-cause mortality after excluding ENGAGE AF-TIMI Edoxaban $30 \mathrm{mg}$, Figure S6: The meta-analysis results for stroke, Figure S6A: The meta-analysis results for stroke after combining study data with respect to doses, Figure S7: The funnel plot for stroke, Figure S8: The meta-analysis results for stroke after excluding ENGAGE AF-TIMI Edoxaban $30 \mathrm{mg}$, Figure S8A: The meta-analysis results for stroke after excluding ENGAGE AF-TIMI Edoxaban $30 \mathrm{mg}$ and combining study data with respect to doses, Figure S9: The funnel plot for stroke after excluding ENGAGE AF-TIMI Edoxaban $30 \mathrm{mg}$, Figure S10: The meta-analysis results for MACE-reanalysis RE-LY -intention-to-treat data, Figure S10A: The meta-analysis results for MACE-reanalysis RELY-intention-to-treat data after comining study data with respect to doses, Figure S11: The funnel plot for MACE-reanalysis RE-LY- intention-to-treat data, Figure S12: The meta-analysis results for MACE-reanalysis RE-LY - intention-to-treat data after excluding ENGAGE AF-TIMI Edoxaban $30 \mathrm{mg}$, Figure S12A: The meta-analysis results for MACE-reanalysis RE-LY-intention-to-treat data after excluding ENGAGE AF-TIMI Edoxaban $30 \mathrm{mg}$ and combining study data with respect to doses, Figure S13: The funnel plot for MACE-reanalysis RE-LY-intention-to-treat data after excluding ENGAGE AF-TIMI Edoxaban $30 \mathrm{mg}$, Figure S14: The meta-analysis results for MACEreanalysis RE-LY - on-treatment data, Figure S14A: The meta-analysis results for MACE-reanalysis RE-LY - on-treatment data after combining study data with respect to doses, Figure S15: The funnel plot for MACE_-reanalysis RE-LY—on-treatment data, Figure S16: The meta-analysis results for MACE-reanalysis RE-LY - on-treatment data after excluding ENGAGE AF-TIMI Edoxaban $30 \mathrm{mg}$, Figure S16A: The meta-analysis results for MACE-reanalysis RE-LY-on-treatment data after excluding ENGAGE AF-TIMI Edoxaban $30 \mathrm{mg}$ and combining study data with respect to doses, Figure S17: The funnel plot for MACE—reanalysis RE-LY—on-treatment data after excluding 
ENGAGE AF-TIMI Edoxaban $30 \mathrm{mg}$, Figure S18: The meta-analysis results for MI, Figure S18A: The meta-analysis results for MI after combining study data with respect to doses, Figure S19: The funnal plot for MI, Figure S20: The meta-analysis results for MI after excluding ENGAGE AF-TIMI Edoxaban $30 \mathrm{mg}$, Figure S20A: The meta-analysis results for MI after excluding ENGAGE AF-TIMI Edoxaban $30 \mathrm{mg}$ and combining study data with respect to doses, Figure S21: The funnel plot for MI after excluding ENGAGE AF-TIMI Edoxaban $30 \mathrm{mg}$, Figure S22: The meta-analysis results for MI-reanalysis RE-LY-intention-to-treat, Figure S22A: The meta-analysis results for MI-reanalysis RE-LY-intention-to-treat data after combining study data with respect to doses, Figure S23: The funnel plot for MI-reanalysis RE-LY-inetntion-to-treat data, Figure S24: The meta-analysis results for MI-reanalysis RE-LY—intentio-to-treat data after excluding ENGAGE AF-TIMI Edoxaban 30 mg, Figure S24A: The meta-analysis results for MI-reanalysis RE-LY-intention-to-treat data after excluding ENGAGE AF-TIMI Edoxaban $30 \mathrm{mg}$ and combining study data with respect to doses, Figure S25: The funnel plot for MI-reanalysis RE-LY-intention-to-treat data after excluding ENGAGE AF-TIMI Edoxaban $30 \mathrm{mg}$, Figure S26: The meta-analysis results for MI-reanalysis RE-LY—on-treatment data, Figure S26A: The meta-analysis results for MI-reanalysis RE-LY-on-treatment data combining study data with respect to doses, Figure S27: The funnel plot for MI—reanalysis RE-LY—on-treatment data, Figure S28: The meta-analysis results for MI-reanalysis RE-LY—on-treatment data after excluding ENGAGE AF-TIMI Edoxaban $30 \mathrm{mg}$, Figure S28A: The meta-analysis results for MI-reanalysis RE-LY - on-treatment data after excluding ENGAGE AF-TIMI Edoxaban $30 \mathrm{mg}$ and combining study data with respect to doses, Figure S29: The funnel plot for MI-reanalysis RE-LY—on-treatment data after excluding ENGAGE AF-TIMI Edoxaban $30 \mathrm{mg}$, Figure S30: The meta-analysis results for stent thrombosis, Figure S30A: The meta-analysis results for stent thrombosis after combining study data with respect to doses, Figure S31: The funnel plot for stent thrombosis, Figure S32 The meta-analysis results for cardiovascular mortality, Figure S32A: The meta-analysis results for cardiovascular mortality after combinig study data with respect to doses, Figure S33: The funnel plot for cardiovascular mortality, Figure S34: The meta-analysis results for cardiovascular mortality after excluding ENGAGE AF-TIMI Edoxaban $30 \mathrm{mg}$, Figure S34A: The meta-analysis results for cardiovascular mortality after excluding ENGAGE AF-TIMI Edoxaban $30 \mathrm{mg}$ and combining study data with respect to doses, Figure S35: The funnel plot for cardiovascular mortality after excluding ENGAGE AF-TIMI Edoxaban 30 mg, Figure S36: The meta-analysis results for cardiovascular mortality-reanalysis RE-LY-intention-to-treat data, Figure S36A: The meta-analysis results for cardiovascular mortality—reanalysis RE-LY_intention-to-treat data after combining study data with respect to doses, Figure S37: The funnel plot for cardiovascular mortality—reanalysis RE-LYintention-to-treat data, Figure S38: The meta-analysis results for cardiovascular mortality-reanalysis RE-LY-intention-to-treat data after excluding ENGAGE AF-TIMI Edoxaban $30 \mathrm{mg}$, Figure S38A: The meta-analysis results for cardiovascular mortality-reanalysis RE-LY-intention-to-treat data after excluding ENGAGE AF-TIMI Edoxaban $30 \mathrm{mg}$ and combining study data with respect to doses, Figure S39: The funnel plot for cardiovascular mortality-reanalysis RE-LY—intention-to-treat data after excluding ENGAGE AF-TIMI Edoxaban $30 \mathrm{mg}$, Figure S40: The meta-analysis results for cardiovascular mortality—reanalysis RE-LY—on-treatment data, Figure S40A: The meta-analysis results for cardiovascular mortality - reanalysis RE-LY —on-treatment data after combining study data with respect to doses, Figure S41: The funnel plot for cardiovascular mortality—reanalysis RE-LYon-treatment data, Figure S42: The meta-analysis results for cardiovascular mortality-reanalysis RE-LY - on-treatment data after excluding ENGAGE AF-TIMI Edoxaban 30 mg, Figure S42A: The meta-analysis results for cardiovascular mortality—reanalysis RE-LY—on-treatment data after excluding ENGAGE AF-TIMI Edoxaban $30 \mathrm{mg}$ and combining study data with respect to doses, Figure S43: The funnel plot for cardiovascular mortality-reanalysis RE-LY_on-treatment data after excluding ENGAGE AF-TIMI Edoxaban 30 mg, Figure S44: The network plot of compared NOAC's and Warfarin, Figure S45: Rankograms for the drugs network showing the probability every treatment being at particular order-MACE**-intention-to-treat data, Figure S46: Rankograms for the drugs network showing the probability every treatment being at particular order-MACE**-on-treatment data, Figure S47: Rankograms for the drugs network showing the probability every treatment being at particular order-MI* data, Figure S48: Rankograms for the drugs network showing the probability every treatment being at particular order-MI** - intention-to-treat data, Figure S49: Rankograms for the drugs network showing the probability every treatment being at particular order- $\mathrm{MI}^{* *}$ on-treatment data, Figure S50: Rankograms for the drugs network showing the probability every treatment being at particular order—stroke data, Figure S51: Rankograms for the drugs network 
showing the probability every treatment being at particular order-overall moratlity data, Additional calculations necessary for the logical sequence of the meta-analysis are provided.

Author Contributions: S.G. conception and design, acquisition of data, analysis and interpretation of data, drafting the manuscript, funding obtaining, M.M. design, acquisition of data, analysis and interpretation of data, drafting the manuscript, J.M.S.-M. drafting the manuscript, critical revision, M.K.-O. drafting the manuscript, critical revision; M.G. drafting the manuscript. All authors have read and agreed to the published version of the manuscript.

Funding: This research received no external funding.

Institutional Review Board Statement: Not applicable. The study is a meta-analysis of the Phase III RCTs. The study was registered in the database PROSPERO ID CRD42020179808.

Informed Consent Statement: Not applicable.

Data Availability Statement: The data that supports the findings of this study are available in the Supplementary Materials of this article.

Acknowledgments: The authors thank JO Medical Solutions for providing medical writing support in accordance with Good Publication Practice (GPP3) guidelines (http: / / www.ismpp.org/gpp3) access date 10 August 2021.

Conflicts of Interest: SG reports personal fees for lectures from Servier, AstraZeneca, Bayer outside the submitted paper, the other authors declare no conflict of interest.

\section{References}

1. Dewilde, W.J.; Oirbans, T.; Verheugt, F.W.; Kelder, J.C.; De Smet, B.J.; Herrman, J.P.; Adriaenssens, T.; Vrolix, M.; Heestermans, A.A.; Vis, M.M.; et al. Use of clopidogrel with or without aspirin in patients taking oral anticoagulant therapy and undergoing percutaneous coronary intervention: An open-label, randomised, controlled trial. Lancet 2013, 381, 1107-1115. [CrossRef]

2. Fiedler, K.A.; Maeng, M.; Mehilli, J.; Schulz-Schuepke, S.; Byrne, R.A.; Sibbing, D.; Hoppmann, P.; Schneider, S.; Fusaro, M.; Ott, I.; et al. Duration of Triple Therapy in Patients Oral Anticoagulation After Drug-Eluting Stent Implantation The ISAR-TRIPLE Trial. J. Am. Coll. Cardiol. 2015, 65, 1619-1629. [CrossRef] [PubMed]

3. Gibson, C.M.; Mehran, R.; Bode, C.; Halperin, J.; Verheugt, F.W.; Wildgoose, P.; Birmingham, M.; Ianus, J.; Burton, P.; Van Eickels, M.; et al. Prevention of Bleeding in Patients with Atrial Fibrillation Undergoing PCI. N. Engl. J. Med. 2016, 375, 2423-2434. [CrossRef] [PubMed]

4. Cannon, C.P.; Bhatt, D.L.; Oldgren, J.; Lip, G.Y.; Ellis, S.G.; Kimura, T.; Maeng, M.; Merkely, B.; Zeymer, U.; Gropper, S.; et al. Dual Antithrombotic Therapy with Dabigatran after PCI in Atrial Fibrillation. N. Engl. J. Med. 2017, 377, 1513-1524. [CrossRef]

5. Lopes, R.D.; Heizer, G.; Aronson, R.; Vora, A.N.; Massaro, T.; Mehran, R.; Goodman, S.G.; Windecker, S.; Darius, H.; Li, J.; et al. Antithrombotic therapy after acute coronary syndrome or PCI in atrial fibrillation. N. Engl. J. Med. 2019, 380, 1509-1524. [CrossRef]

6. Vranckx, P.; Valgimigli, M.; Eckardt, L.; Tijssen, J.; Lewalter, T.; Gargiulo, G.; Batushkin, V.; Campo, G.; Lysak, Z.; Vakaliuk, I.; et al. Edoxaban-based versus vitamin $\mathrm{K}$ antagonist-based antithrombotic regimen after successful coronary stenting in patients with atrial fibrillation (ENTRUST-AF PCI): A randomised, open-label, phase 3b trial. Lancet 2019, 394, 1335-1343. [CrossRef]

7. Golwala, H.B.; Cannon, C.P.; Steg, P.G.; Doros, G.; Qamar, A.; Ellis, S.G.; Oldgren, J.; Ten Berg, J.M.; Kimura, T.; Hohnloser, S.H.; et al. Safety and efficacy of dual vs. triple antithrombotic therapy in patients with atrial fibrillation following percutaneous coronary intervention: A systematic review and meta-analysis of randomized clinical trials. Eur. Heart J. 2018, 39, 1726-1735. [CrossRef]

8. Haller, P.M.; Sulzgruber, P.; Kaufmann, C.; Geelhoed, B.; Tamargo, J.; Wassmann, S.; Schnabel, R.B.; Westermann, D.; Huber, K.; Niessner, A.; et al. Bleeding and ischemic outcomes in patients treated with dual or triple antithrombotic therapy-Systematic review and meta-analysis. Eur. Heart J. Cardiovasc. Pharmacother. 2019, 5, 226-236. [CrossRef]

9. Grajek, S.; Olasinska-Wisniewska, A.; Michalak, M.; Ritter, S.S. Triple versus double antithrombotic therapy in patients with atrial fibrillation and stent implantation: A meta-analysis of randomized trials. Kardiologia Polska 2019, 77, 837-845. [CrossRef]

10. Lopes, R.D.; Hong, H.; Harskamp, R.E.; Bhatt, D.L.; Mehran, M.; Cannon, C.P.; Granger, C.B.; Verheugt, F.W.A.; Li, J.; Berg, J.M.; et al. Optimal Antithrombotic Regimens for Patients With Atrial Fibrillation Undergoing Percutaneous Coronary Intervention An Updated Network Meta-analysis. JAMA Cardiol. 2020, 5, 582-589. [CrossRef]

11. Eyileten, C.; Postula, M.; Jakubik, D.; Toma, A.; Mirowska-Guzel, D.; Patti, G.; Renda, G.; Siller-Matula, J.M. Non-Vitamin K Oral Anticoagulants (NOAC) Versus Vitamin K Antagonists (VKA) for Atrial Fibrillation with Elective or Urgent Percutaneous Coronary Intervention: A Meta-Analysis with a Particular Focus on Combination Type. J. Clin. Med. 2020, 9, 1120. [CrossRef] 
12. Gargiulo, G.; Goette, A.; Tijssen, J.; Eckardt, L.; Lewalter, T.; Vranckx, P.; Valgimigli, M. Safety and efficacy outcomes of double vs. triple antithrombotic therapy in patients with atrial fibrillation following percutaneous coronary intervention: A systematic review and meta-analysis of non-vitamin $\mathrm{K}$ antagonist oral anticoagulant-based randomized clinical trials. Eur. Heart J. 2019, 40, 3757-3767. [PubMed]

13. Andò, G.; Costa, F. Double or triple antithrombotic therapy after coronary stenting and atrial fibrillation: A systematic review and meta-analysis of randomized clinical trials. Int. J. Cardiol. 2020, 302, 95-102. [CrossRef] [PubMed]

14. Hindricks, G.; Potpara, T.; Dagres, N.; Arbelo, E.; Bax, J.J.; Blomström-Lundqvist, C.; Boriani, G.; Castella, M.; Dan, G.-A.; Dilaveris, P.E.; et al. 2020 ESC Guidelines for the diagnosis and management of atrial fibrillation developed in collaboration with the European Association for Cardio-Thoracic Surgery (EACTS). Eur. Hear. J. 2020, 42, 373-498. [CrossRef]

15. Collet, J.P.; Thiele, H.; Barbato, E.; Berthelemy, O.; Bauersachs, J.; Bhatt, D.L.; Dendale, P.; Dorobantu, M.; Edvardsen, T.; Folliguet, T.; et al. 2020 ESC Guidelines for the management of acute coronary syndromes in patients presenting without persistent ST-segment elevation. Eur. Heart J. 2021, 42, 1289-1367. [CrossRef] [PubMed]

16. Uchino, K.; Hernandez, A.V. Dabigatran Association with Higher Risk of Acute Coronary Events Meta-analysis of Noninferiority Randomized Controlled Trials. Dabigatran Association with Higher Risk of Acute Coronary Events Meta-analysis of Noninferiority Randomized Controlled Trials. Arch. Intern. Med. 2012, 172, 397-402. [CrossRef] [PubMed]

17. Mak, K.H. Coronary and mortality risk of novel oral antithrombotic agents: A meta-analysis of large randomised trials. BMJ Open 2012, 2, e001592. [CrossRef]

18. Chatterjee, S.; Sharma, A.; Uchino, K.; Biondi-Zoccai, G.; Lichstein, E.; Murkherjee, D. Rivaroxaban and risk of myocardial infarction: Insights from a meta-analysis and trial sequential analysis of randomized clinical trials. Coron. Artery Dis. 2013, 24, 628-635. [CrossRef]

19. Artang, R.; Rome, E.; Nielsen, J.D.; Vidaillet, H.J. Meta-Analysis of Randomized Controlled Trials on Risk of Myocardial Infarction from the Use of Oral Direct Thrombin Inhibitors. Am. J. Cardiol. 2013, 112, 1973-1979. [CrossRef]

20. Loke, Y.K.; Pradhan, S.; Yeong, J.K.; Kwok, C.S. Comparative coronary risks of apixaban, rivaroxaban and dabigatran: A metaanalysis and adjusted indirect comparison. Br. J. Clin. Pharmacol. 2014, 78, 707-717. [CrossRef]

21. Tornyos, A.; Kehl, D.; D’Ascenzo, F.; Komócsi, A. Risk of Myocardial Infarction in Patients with Long-Term Non-Vitamin K Antagonist Oral Anticoagulant Treatment. Prog. Cardiovasc. Dis. 2016, 58, 483-494. [CrossRef]

22. Morimoto, T.; Crawford, B.; Wada, K.; Ueda, S. Comparative efficacy and safety of novel oral anticoagulants in patients with atrial fibrillation: A network meta-analysis with the adjustment for the possible bias from open label studies. J. Cardiol. 2015, 66, 466-474. [CrossRef] [PubMed]

23. Connolly, S.J.; Ezekowitz, M.D.; Yusuf, S.; Eikelboom, J.; Oldgren, J.; Pakekh, A.; Pogue, A.; Reilly, P.A.; Themeles, E.; Varrone, J.; et al. RE-LY Steering Committee and Investigators* Dabigatran versus warfarin in patients with atrial fibrillation. N. Engl. J. Med. 2009, 361, 1139-1151. [CrossRef] [PubMed]

24. Patel, M.P.; Mahaffey, K.W.; Garg, J.; Pan, P.; Singer, D.E.; Hacke, W.; Breithardt, G.; Halperin, J.L.; Hankey, G.J.; Piccini, J.P.; et al. Rivaroxaban Versus Warfarin in Nonvalvular Atrial Fibrillation. N. Engl. J. Med. 2011, 365, 883-891. [CrossRef] [PubMed]

25. Granger, C.B.; Alexander, J.H.; Mcmurray, J.; Lopes, R.D.; Hylek, E.M.; Hanna, M.; Al-Khalidi, H.R.; Ansell, J.; Atar, D.; Avezum, A.; et al. Apixaban versus Warfarin in Patients with Atrial Fibrillation. N. Engl. J. Med. 2011, 365, 981-992. [CrossRef] [PubMed]

26. Giugliano, R.; Ruff, C.T.; Braunwald, E.; Murphy, A.; Wiviott, S.D.; Halperin, J.L.; Waldo, A.L.; Ezekowitz, M.D.; Weitz, J.I.; Špinar, J.; et al. Edoxaban versus Warfarin in Patients with Atrial Fibrillation. N. Engl. J. Med. 2013, 369, 2093-2104. [CrossRef] [PubMed]

27. Hohnloser, S.H.; Oldgren, J.; Yang, S.; Wallentin, L.; Ezekowitz, M.; Reilly, P.; Eikelboom, J.; Brueckmann, M.; Yusuf, S.; Connolly, S.J. Myocardial Ischemic Events in Patients With Atrial Fibrillation Treated With Dabigatran or Warfarin in the RE-LY (Randomized Evaluation of Long-Term Anticoagulation Therapy) Trial. Circulation 2012, 125, 669-676. [CrossRef]

28. Bucher, H.C.; Guyatt, G.H.; Griffith, L.E.; Walter, S.D. The results of direct and indirect treatment comparisons in meta-analysis of randomized controlled trials. J. Clin. Epidemiol. 1997, 50, 683-691. [CrossRef]

29. Song, F.; Loke, Y.K.; Walsh, T.; Glenny, A.-M.; Eastwood, A.J.; Altman, D.G. Methodological problems in the use of indirect comparisons for evaluating healthcare interventions: Survey of published systematic reviews. BMJ 2009, 338, b1147. [CrossRef]

30. Lumley, T. Network meta-analysis for indirect treatment comparisons. Statist. Med. 2002, 21, 2313-2324. [CrossRef]

31. Salanti, G.; Ades, A.E.; Ioannidis, J.P.A. Graphical methods and numerical summaries for presenting results from multipletreatment meta-analysis: An overview and tutorial. J. Clin. Epidemiol. 2011, 64, 163-171. [CrossRef]

32. Connolly, S.J.; Eikelboom, J.; Joyner, C.; Diener, H.-C.; Hart, R.; Golitsyn, S.; Flaker, G.; Avezum, A.; Hohnloser, S.H.; Diaz, R.; et al. Apixaban in Patients with Atrial Fibrillation. N. Engl. J. Med. 2011, 364, 806-817. [CrossRef] [PubMed]

33. Connolly, S.J.; Ezekowitz, M.D.; Yusuf, S.; Reilly, P.A.; Wallentin, L. Newly identified events in the RE-LY Trial. N. Engl. J. Med. 2010, 363, 1875-1886. [CrossRef] [PubMed]

34. Ruff, C.h.T.; Giugliano, R.P.; Braunwald, E.; Hoffman, E.B. Comparison of the efficacy and safety of new oral anticoagulants with warfarin in patients with atrial fibrillation: A meta-analysis of randomised trials. Lancet 2014, 383, 955-962. [CrossRef]

35. Larsen, T.B.; Rasmussen, L.H.; Skjøth, F.; Due, K.M.; Callréus, T.; Rosenzweig, M.; Lip, G.Y. Efficacy and Safety of Dabigatran Etexilate and Warfarin in "Real-World" Patients With Atrial Fibrillation. J. Am. Coll. Cardiol. 2013, 61, 2264-2273. [CrossRef] 
36. Graham, D.J.; Reichman, M.E.; Wernecke, M.; Zhang, R.; Southworth, M.R.; Levenson, M.; Sheu, T.-C.; Mott, K.; Goulding, M.R.; Houstoun, M.; et al. Cardiovascular, Bleeding, and Mortality Risks in Elderly Medicare Patients Treated With Dabigatran or Warfarin for Nonvalvular Atrial Fibrillation. Circulation 2015, 131, 157-164. [CrossRef]

37. Lauffenburger, J.C.; Farley, J.F.; Gehi, A.K.; Rhoney, D.H.; Brookhart, M.A.; Fang, G. Effectiveness and Safety of Dabigatran and Warfarin in Real-World US Patients With Non-Valvular Atrial Fibrillation: A Retrospective Cohort Study. J. Am. Hear. Assoc. 2015, 4. [CrossRef] [PubMed]

38. Lee, C.h.J.; Gerds, T.A.; Carlson, N.; Bonde, A.N.; Gislason, G.H.; Lamberts, M.; Olesen, J.B.; Pallisgaard, J.L.; Hansen, M.L.; Torp-Pedersen, C.; et al. Risk of Myocardial Infarction in Anticoagulated Patients With Atrial Fibrillation. J. Am. Coll. Cardiol. 2018, 72, 17-26. [CrossRef] [PubMed]

39. Wei, A.H.; Gu, Z.C.; Zhang, C.; Ding, Y.F.; Liu, D.; Li, J.; Liu, X.Y.; Lin, H.W.; Pu, J. Increased risk of myocardial infarction with dabigatran etexilate: Fact or fiction? A critical meta-analysis of over 580,000 patients from integrating randomized controlled trials and real-world studies. Int. J. Cardiol. 2018, 267, 1-7. [CrossRef]

40. Larsen, T.B.; Rasmussen, L.H.; Gorst-Rasmussen, A.; Skjøth, F.; Rosenzweig, M.; Lane, D.A.; Lip, G.Y. Myocardial Ischemic Events in 'Real World' Patients with Atrial Fibrillation Treated with Dabigatran or Warfarin. Am. J. Med. 2013, 127, 329-336.e4. [CrossRef] [PubMed]

41. Eilkenboom, J.W.; Weitz, J.I. Dabigatran and risk of myocardial infarction. Nat. Rev. Cardiol. 2012, 9, $260-262$.

42. Sipahi, I.; Celik, S.; Akyol, A. Dabigatran's "Real-World" data about risk of Myocardial infarction and gastrointestinal bleeding contradicts with randomized trials. J. Am. Coll. Cardiol. 2013, 62, 945-946. [CrossRef]

43. Larsen, T.B.; Rasmussen, L.H.; Skjoth, F.; Margrete, K.; Callreus, T.; Rosenzweig, M.; Lip, G.Y. Reply: Dabigatran's “Real World” data about risk of myocardial infarction and gastrointestinal bleeding contradics with randomized trials. J. Am. Coll. Cardiol. 2013, 62, 946-947. [CrossRef]

44. Hohnloser, S.H.; Eikelboom, J.W. Direct oral anticoagulants and myocardial infarction. The dust is settling. J. Am. Coll. Cardiol. 2018, 72, 27-28. [CrossRef]

45. Polzin, A.; Dannenberg, L.; Wolff, G.; Zeus, T.; Kelm, M.; Petzold, T. Increased risk of myocardial infarction with dabigatran etexilate: Fact or fiction? A critical meta-analysis from integrating randomized controlled trials and real world studies: Wine or spritzer? Letter to Editor. Int. J. Cardiol. 2018, 270, 82. [CrossRef]

46. Lip, G.Y.H.; Larsen, T.B.; Skjøth, F.; Rasmussen, L.H. Indirect Comparisons of New Oral Anticoagulant Drugs for Efficacy and Safety When Used for Stroke Prevention in Atrial Fibrillation. Am. Coll. Cardiol. 2012, 60, 738-746. [CrossRef]

47. Kupó, P.; Szakács, Z.; Solymár, M.; Habon, T.; Czopf, L.; Hategan, L.; Csányi, B.; Borbás, J.; Tringer, A.; Varga, G.; et al. Direct Anticoagulants and Risk of Myocardial Infarction, a Multiple Treatment Network Meta-Analysis. Angiology 2019, 71, 27-37. [CrossRef]

48. Dale, B.; Eikelboom, J.W.; Weitz, J.I.; Young, E.; Paikin, J.S.; Coppens, M.; Whitlock, R.P.; Connolly, S.J.; Ginsberg, J.S.; Hirsh, J. Dabigatran attenuates thrombin generation to a lesser extent than warfarin: Could this explain their differential effects on intracranial hemorrhage and myocardial infarction? J. Thromb. Thrombolysis 2013, 35, 295-301. [CrossRef] [PubMed]

49. Furugohri, T.; Sugiyama, N.; Morishima, Y.; Shibano, T. Antithrombin-independent thrombin inhibitors, but not direct factor Xa inhibitors, enhance thrombin generation in plasma through inhibition of thrombin-thrombomodulin-protein C system. J. Thromb. Haemost. 2011, 106, 1076-1083.

50. Achilles, A.; Mohring, A.; Dannenberg, L.; Grandoch, M.; Hohlfeld, T.; Fischer, J.W.; Levkau, B.; Kelm, M.; Zeus, T.; Polzin, A. Dabigatran enhances platelet reactivity and platelet thrombin receptor expression in patients with atrial fibrillation. J. Thromb. Haemost. 2017, 15, 473-476. [CrossRef] [PubMed]

51. Christersson, C.; Oldgren, J.; Wallentin, L.; Siegbahn, A. Treatment with an oral direct thrombin inhibitor decreases platelet activity but increases markers of inflammation in patients with myocardial infarction. J. Intern. Med. 2011, 270, 215-223. [CrossRef] 